\title{
Complete closure of artificial gastric ulcer after endoscopic submucosal dissection by combined use of a single over-the-scope clip and through-the-scope clips (with videos)
}

\author{
Satoshi Maekawa $\cdot$ Ryosuke Nomura $\cdot$ \\ Takayuki Murase $\cdot$ Yasuyoshi Ann • \\ Masaru Harada
}

Received: 9 April 2014/Accepted: 1 July 2014/Published online: 23 July 2014

(C) Springer Science+Business Media New York 2014

\begin{abstract}
Background A 5-7 day hospital stay is usually needed after endoscopic submucosal dissection (ESD) of gastric tumor because of the possibility of delayed perforation or bleeding. The aim of this study was to evaluate the efficacy of combined use of a single over-the-scope clip (OTSC) and through-the-scope clips (TTSCs) to achieve complete closure of artificial gastric ulcer after ESD.

Methods We prospectively studied 12 patients with early gastric cancer or gastric adenoma. We performed complete closure of post-ESD artificial gastric ulcer using a combination of a single OTSC and TTSCs.

Results Mean size of post-ESD artificial ulcer was $54.6 \mathrm{~mm}$. The mean operating time for the closure procedure was $15.2 \mathrm{~min}$., and the success rate was $91.7 \%$ (11/ 12). Patients who underwent complete closure of post-ESD artificial gastric ulcer could be discharged the day after ESD and the closing procedure.

Conclusions Complete closure of post-ESD artificial gastric ulcer using a combination of a single OTSC and TTSCs is useful for shortening the period of hospitalization and reducing treatment cost.
\end{abstract}

Electronic supplementary material The online version of this article (doi:10.1007/s00464-014-3725-1) contains supplementary material, which is available to authorized users.

S. Maekawa $(\bowtie) \cdot$ R. Nomura $\cdot$ T. Murase · Y. Ann Department of Gastroenterological Medicine, Japan Labour Health and Welfare Organization Niigata Rosai Hospital, 1-7-12 Touncho, Joetsu, Niigata 942-8502, Japan e-mail: s5083m@niirou.jp

M. Harada

Third Department of Internal Medicine, University of Occupational and Environmental Health, Kitakyushu, Japan
Keywords Endoscopic submucosal dissection . Complete closure of post-ESD artificial gastric ulcer . Over-the-scope clip · Through-the-scope clips

Endoscopic treatment of gastric cancer has made great advances because of the introduction of endoscopic submucosal dissection (ESD) [1]. ESD has made it possible to remove large lesions exceeding $2 \mathrm{~cm}$ and has become a popular procedure for the treatment of gastrointestinal (GI) tract tumors.

However, ESD is time-consuming and technically difficult, and complications such as perforation and bleeding sometimes occur. Even when ESD is successfully performed, there is a risk of delayed perforation or bleeding for several days after ESD due to the artificial ulcer. Therefore, 5-7 days in-hospital after ESD is generally needed.

Through-the-scope clips (TTSCs) have been available for nearly 20 years, and applications include the treatment of GI bleeding, closure of perforations and fistulae, and anchoring of feeding tubes [2-4]. Although these devices are relatively inexpensive and easy to use, they have limited opening widths and closing strengths and are usually ineffective in the case of fibrotic tissue. Closure of postESD artificial gastric ulcer with TTSCs is not always feasible, especially for larger defects after ESD [5].

One recent study demonstrated the feasibility and use of a novel over-the-scope clip (OTSC) system (Ovesco Endoscopy AG, Tübingen, Germany) [6]. Experimental studies have demonstrated the ability of the OTSC to close perforations and control arterial bleeding [7-10].

Closure of post-ESD artificial gastric ulcer is not common in the present clinical setting. We considered that complete closure of post-ESD artificial gastric ulcer would be useful to prevent delayed bleeding and perforation and 
shorten the length of hospitalization. It is difficult to completely close post-ESD artificial gastric ulcer using a single OTSC or only TTSCs, because the gastric mucosa is thick and hard. We considered that a therapy combining a single OTSC and multiple TTSCs might facilitate the closure procedure.

Here, we report for the first time a closure technique for post-ESD artificial gastric ulcer using a combination of a single OTSC and multiple TTSCs.

\section{Patients and methods}

The indications for inclusion in this study were patients with early gastric cancer or gastric adenoma $3 \mathrm{~cm}$ or less in diameter which did not involve the cardiac or pyloric region. 12 patients fulfilled these indications. They were admitted to Japan Labour Health and Welfare Organization Niigata Rosai Hospital from June 2013 to March 2014. Written informed consent was obtained from all patients, and the ethics committee of our hospital approved this study.

The OTSC system is mounted onto the tip of a high definition gastroscope (Olympus GIF-Q260 J; diameter of $9.9 \mathrm{~mm}$; working channel of $3.2 \mathrm{~mm}$; Olympus, Tokyo, Japan) in the same manner as a band ligator device. In this study, we used the "traumatic" version of OTSC, which has pointed teeth (clip length; $10 \mathrm{~mm}$ ). The clip is preloaded into the applicator cap in an open state. The OTSC consists of a shape-memory nitinol alloy, which returns to its initial shape when it is released from the applicator, causing closure of the clip. The clip is deployed by stretching a wire using a hand wheel mounted on the working-channel access port of the endoscope. The OTSC Twin Grasper (Ovesco Endoscopy, Tübingen, Germany), deployed through the working channel, was used to facilitate approximation of the tissue before closure (Fig. 1). The Twin Grasper has two independently movable lateral claws. Thus, all layers of both incision edges can be

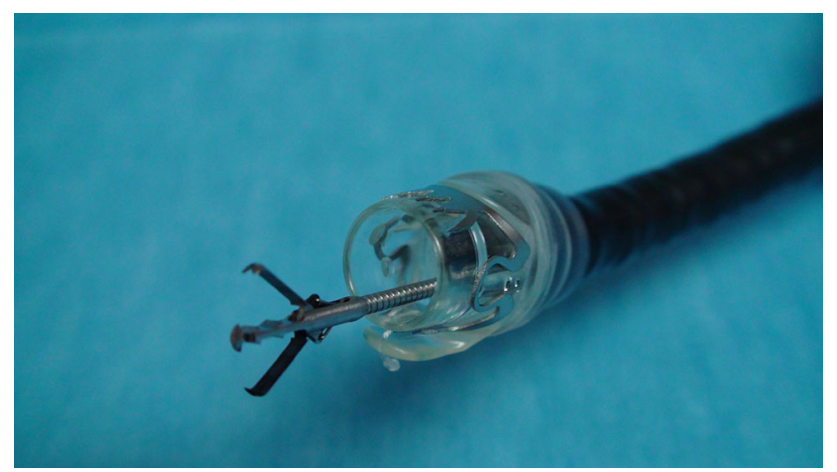

Fig. 1 The over-the-scope clip (OTSC) Twin Grasper, which was used to facilitate approximation of the tissue before closure grasped separately and approximated in preparation for full-thickness closure with the OTSC.

The closure process was as follows: (1) ESD caused formation of an artificial ulcer (Fig. 2A). (2) The lateral edge of the artificial ulcer was grasped by one arm of the OTSC Twin Grasper (Fig. 2B). (3) The other opposing edge of the artificial ulcer was grasped with the second arm of the OTSC Twin Grasper, and the two sides of the artificial ulcer were brought into complete contact (Fig. 2C). (4) The re-apposed tissue was pulled into the OTSC cap at the tip of the endoscope. The grasper, including apposed tissue, was withdrawn into the cap before the clip was applied, then (5) sufficient suction was maintained to aspirate the tissue surrounding the artificial ulcer into the cap (Fig. 2D). (6) The OTSC was then released by turning a wheel on the shaft of the endoscope, similar to the endoscopic band ligation method (Fig. 2E). (7) TTSCs, such as ZEOCLIP (Zeon Medical Inc., Tokyo, Japan) or Rotatable Clip Fixing Device, EZ Clip, long type, HX-610135L (Olympus Medical Systems Corp., Tokyo, Japan) were then used to close the open part of the ulcer adjacent to the released OTSC (Fig. 2F). (8) Finally endoscopic inspection was performed to visually confirm complete closure (Fig. 2G).

\section{Results}

Characteristics and outcomes of the 12 patients are summarized in Table 1. Their average age was $71.0 \pm 8.0$ years (mean \pm standard deviation [SD]). The upper third:middle third:lower third ratio of tumor location was 3:6:3. Mean tumor size was $19.5 \mathrm{~mm}$, and mean size of resected specimen $39.3 \mathrm{~mm}$. The mean operating time for resection was $47.9 \mathrm{~min}$. The rate of en-bloc and margin-free resection was $100 \%$. Early gastric cancer:gastric adenoma was 9:3. Mean size of the artificial ulcer was $54.6 \mathrm{~mm}$. The mean operating time for closure of post-ESD artificial gastric ulcer was $15.1 \mathrm{~min}$. The rate of complete closure of post-ESD artificial gastric ulcer was $91.7 \%$ (11/12). Mean numbers of OTSC and TTSCs were 1 and 5.8 per patient, respectively. The OTSC and TTSCs dropout rate and the rate of discharge on the day following ESD were $0 \%$ and $91.7 \%$, respectively. The OTSC dropout rate after ESD after two months was $8.3 \%$. The complication rate (ex. delayed perforation, postoperative bleeding and gastric stenosis) was $0 \%$.

The lesions of three patients (Patients no.1, 10, 11) were located in the upper third of the stomach. In the complete closure procedure, the center of the artificial ulcer was grasped by an OTSC to lower the ulcer as much as possible, and TTSCs were used to reinforce the open parts of the ulcer on the oral and anal sides of the OTSC (Video 1). 
Fig. 2 Endoscopic view of the over-the-scope clip (OTSC) closure procedure: A The artificial ulcer was created by the ESD. B The lateral edge of the artificial ulcer was grasped by one arm of the OTSC Twin Grasper. C The other opposing edge of the artificial ulcer was grasped with the second arm of the OTSC Twin Grasper. D the re-apposed tissue was pulled into the OTSC cap, and sufficient suction was maintained to aspirate the tissue surrounding the artificial ulcer into the cap. E The OTSC was released by turning a wheel on the shaft of the endoscope.

F Through-the-scope clips (TTSCs) were used to close the open ulcer part around released OTSC. G, Endoscopic inspection was performed for visual confirmation of complete closure
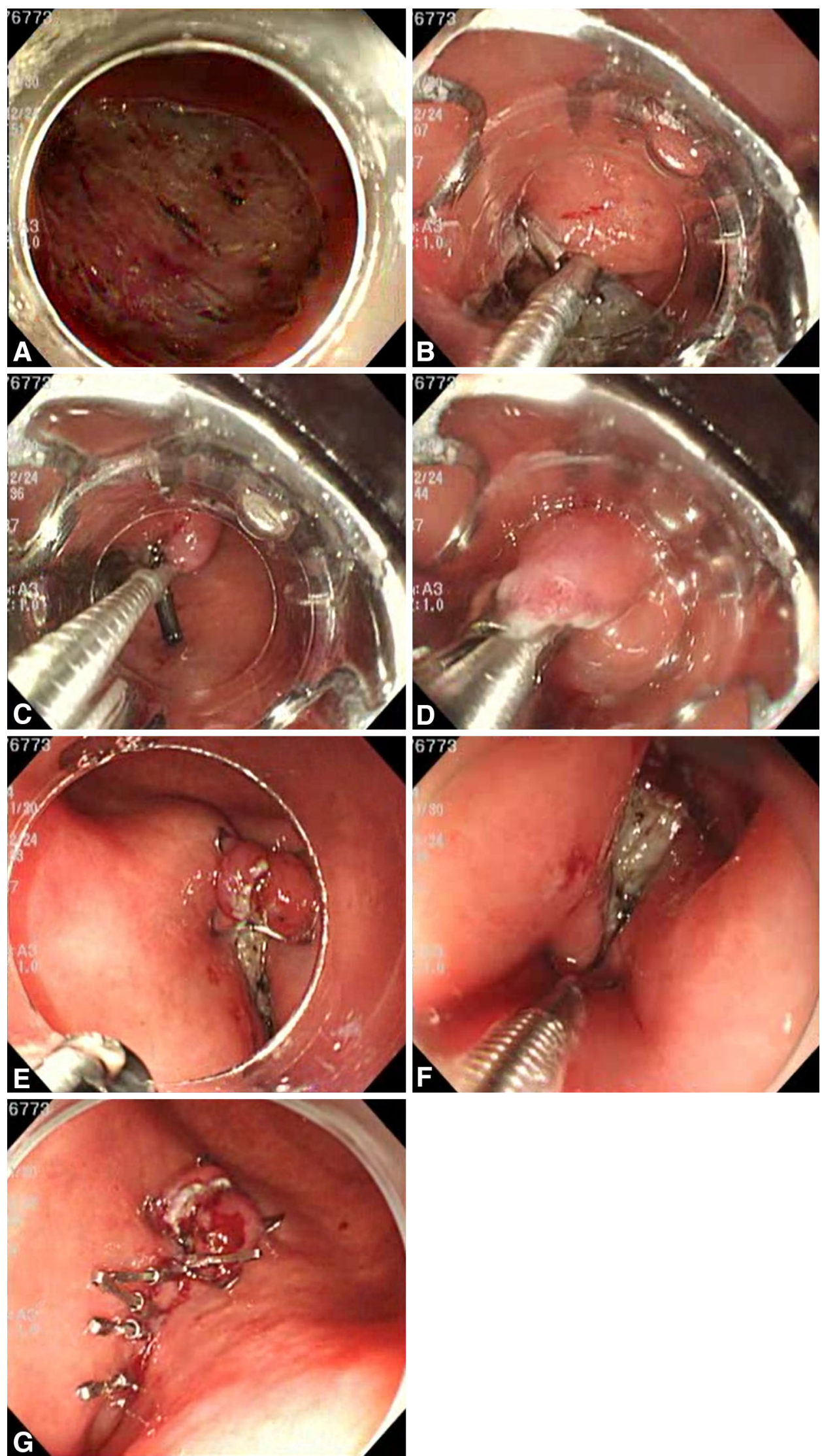
Table 1 Characteristics and outcomes of study patients

\begin{tabular}{|c|c|c|c|c|c|c|c|c|c|c|c|}
\hline No. & Sex & Age & $\begin{array}{l}\text { Location } \\
\text { (U/M/L) }\end{array}$ & $\begin{array}{l}\text { Tumor } \\
\text { size }(\mathrm{mm})\end{array}$ & $\begin{array}{l}\text { Size of } \\
\text { resected } \\
\text { specimen } \\
(\mathrm{mm})\end{array}$ & $\begin{array}{l}\text { Resection } \\
\text { time } \\
(\min )\end{array}$ & $\begin{array}{l}\text { Size of } \\
\text { artificial } \\
\text { ulcer }(\mathrm{mm})\end{array}$ & $\begin{array}{l}\text { Complete } \\
\text { closure } \\
\text { time }(\min )\end{array}$ & $\begin{array}{l}\text { OTSC } \\
\text { (No.) }\end{array}$ & $\begin{array}{l}\text { TTSCs } \\
\text { (No.) }\end{array}$ & $\begin{array}{l}\text { Days of } \\
\text { hospitalization }\end{array}$ \\
\hline 1 & $\mathrm{M}$ & 64 & $\mathrm{U}$ & 18 & 32 & 37 & 40 & 34 & 1 & 10 & 2 \\
\hline 2 & $\mathrm{M}$ & 65 & $\mathrm{M}$ & 15 & 28 & 43 & 45 & 16 & 1 & 5 & 2 \\
\hline 3 & $\mathrm{M}$ & 60 & M & 19 & 44 & 74 & 55 & 8 & 1 & 5 & 2 \\
\hline 4 & $\mathrm{M}$ & 78 & $\mathrm{M}$ & 18 & 40 & 38 & 55 & 15 & 1 & 10 & 2 \\
\hline 5 & $\mathrm{M}$ & 78 & $\mathrm{M}$ & 25 & 43 & 37 & 60 & 18 & 1 & 6 & 2 \\
\hline 6 & $\mathrm{M}$ & 64 & $\mathrm{~L}$ & 22 & 44 & 48 & 50 & 9 & 1 & 5 & 2 \\
\hline 7 & $\mathrm{M}$ & 79 & $\mathrm{M}$ & 22 & 48 & 76 & 60 & 7 & 1 & 3 & 2 \\
\hline 8 & $\mathrm{~F}$ & 74 & $\mathrm{~L}$ & 15 & 35 & 25 & 50 & - & 1 & 0 & 4 \\
\hline 9 & $\mathrm{M}$ & 74 & $\mathrm{M}$ & 24 & 42 & 55 & 60 & 9 & 1 & 5 & 2 \\
\hline 10 & $\mathrm{~F}$ & 77 & $\mathrm{U}$ & 24 & 40 & 42 & 70 & 13 & 1 & 9 & 2 \\
\hline 11 & $\mathrm{M}$ & 78 & $\mathrm{U}$ & 20 & 45 & 76 & 60 & 14 & 1 & 4 & 2 \\
\hline 12 & $\mathrm{M}$ & 60 & $\mathrm{~L}$ & 12 & 30 & 24 & 50 & 24 & 1 & 7 & 2 \\
\hline
\end{tabular}

OTSC over-the-scope clip, TTSCs through-the-scope clips

The lesions of six patients (Patients no. 2-5, 7, 9) were located in the middle third of the stomach. The lesions of four of these six patients (Patients no. 2-5) were located in the lesser curvature side and on the greater curvature side in the remaining two patients (Patients no.7, 9). In the complete closure procedure at the lesser curvature side in the middle third of the stomach, the center of the artificial ulcer was grasped by an OTSC to lower the ulcer as much as possible, and TTSCs were used to reinforce the open parts of the ulcer on the oral and anal sides of the OTSC (Video 2). In the complete closure procedure of the greater curvature side in the middle third of the stomach, the anal side of the artificial ulcer was grasped by an OTSC to lower the ulcer, and TTSCs were used to reinforce the open part of the ulcer on the oral side of the OTSC.

The lesions of three patients (Patients no. 6, 8, 12) were located in the lower third of the stomach. In the complete closure procedure of 2 patients (Patients no.6, 12), the anal side of the artificial ulcer was grasped by an OTSC to lower the ulcer, and TTSCs were used to reinforce the open part of the ulcer on the oral side of the OTSC (Video 3). In one patient (No. 8), we were not able to completely close the post-ESD artificial gastric ulcer. In this patient, we could not reinforce the open part of the ulcer by TTSCs, because the lower third was very narrow, and the OTSC, which had been released toward the oral side of the artificial ulcer, interfered with the TTSCs.

\section{Discussion}

ESD-associated complications such as perforation and bleeding are still serious considerations in the treatment of gastrointestinal tract tumors. Some studies have shown that postoperative bleeding occurs in $6-16 \%$ of patients after gastric ESD [11-13]. We therefore considered that complete closure of post-ESD artificial gastric ulcer would decrease exposure of the submucosal vessels to gastric acid, pepsin, mechanical stimuli, and decrease postoperative bleeding. In the present study, we were able to successfully close artificial gastric ulcers after ESD using a single OTSC and multiple TTSCs in all 13 patients without postoperative bleeding.

There are few reports of closure of post-gastric ESD as compared with post-colorectal ESD. We consider that the main reason is difficulty of closing a large mucosal defect, because gastric mucosa is thick and hard. Mucosal closure with TTSCs is not always feasible, especially for larger defects after ESD [6]. The complete closure of post-ESD artificial gastric ulcer using TTSCs alone is technically very difficult, and the rate of complete closure was $62 \%(37 / 60)$, far lower than with our technique [91.7\% (11/12)] [6]. There is a previously described method for closure of post-ESD artificial gastric ulcer with a detachable snare and clips [14]. This procedure did not seem to be easy, and the rate of complete closure of post-ESD artificial gastric ulcer was $61 \%(16 / 26)$, which is lower than that of the present study.

Recently Kantsevoy et al. [15] reported the closure of large post-ESD defects with the Overstitch endoscopic suturing device which has been specifically designed for tissue approximation. The rate of complete closure of postESD artificial gastric ulcer was $100 \%$ (4/4), but the procedure appears technically difficult, and its use has not become widespread.

Although OTSC is a new device, it is now in use throughout the world. It enables the closure of GI defects (fistulae, perforation sites, leaks) and stops severe bleeding from large lesions of the GI tract [7-10]. OTSC surpasses 
other techniques in terms of breadth and closure power and must therefore improve therapeutic options in endoscopy. We considered that post-ESD artificial gastric ulcer could be closed to some extent by a single OTSC although complete closure of large ulcer is difficult with only a single OTSC. Accordingly, we performed a combination therapy involving a single OTSC and multiple TTSCs to achieve complete closure of post-ESD artificial gastric ulcer. It was relatively easy to completely close post-ESD artificial gastric ulcer with TTSCs after a single OTSC was used, because both edges were strongly grasped by the single OTSC. From our experience, we consider that the anal side of the artificial ulcer should be grasped by the OTSC for lesions in the lower third and greater curvature side of the stomach, because clipping is difficult to perform on the anal side of the OTSC. On the other hand, for lesions in other areas of the stomach, the center of the artificial ulcer should be grasped by the OTSC to lower the ulcer as much as possible. In any case, our post-ESD artificial gastric ulcer closure technique is technically easy and does not need special training.

The closure technique allowed us to discharge our patients after only 2 days instead of the traditional 5-7 days and resulted in significant cost savings. Although we planned for a 2-day hospital stay, surgery on an outpatient basis may be possible using our technique.

Our study had several limitations. First, ESD cases involving the cardiac or pyloric region were not indicated for this closure procedure, because there is a high risk of stenosis after ESD. Second, ESD cases for very extensive tumors were not indicated, because it is technically difficult. Therefore, in this study, we selected patients with early gastric cancer or gastric adenoma $3 \mathrm{~cm}$ or less which did not involve the cardiac or pyloric region. Third, this closure procedure was not indicated when the lower third of the stomach was very narrow, because it is technically difficult. In fact, we were unable to completely close the post-ESD artificial gastric ulcer in one patient in our study for this reason.

In conclusion, we consider that our complete closure method of artificial gastric ulcer after ESD is useful for shortening the period of hospitalization and reducing treatment cost. However, further investigations will be needed to establish the appropriate role of the closure method.

Disclosures S. Maekawa, R. Nomura, T. Murase, Y. Ann, and M Harada have no conflicts of interest or financial ties to disclose.

\section{References}

1. Ono H, Hasuike N, Inui T, Tanizawa K, Ikehara H, Yamaguchi Y, Otake Y, Matsubayashi H (2008) Usefulness of a novel electrosurgical knife, the insulation-tipped diathermic knife-2, for endoscopic submucosal dissection of endoscopic submucosal dissection of early gastric cancer. Gastric Cancer 11(1):47-52. doi:10.1007/s10120-008-0452-0

2. Raju GS, Gajula L (2004) Endoclips for GI endoscopy. Gastrointest Endosc 59:267-279

3. Qadeer MA, Dumot JA, Vargo JJ, Lopez AR, Rice TW (2007) Endoscopic clips for closing esophageal perforations: case report and pooled analysis. Gastrointest Endosc 66:605-611

4. Chuttani R, Barkun A, Carpenter S, Chotiprasidhi P, Ginsberg GG, Hussain N, Liu Julia Silverman W, Taitelbuam G, Petersen B (2006) Endoscopic clip application devices. Gastrointest Endosc 63:746-750

5. Choi KD, Jung HY, Lee GH, Oh TH, Jo JY, Song HJ, Hong SS, Kim JH (2008) Application of metal hemoclips for closure of endoscopic mucosal resection-induced ulcers of the stomach to prevent delayed bleeding. Surg Endosc 22:1882-1886

6. Kirschniak A, Kratt T, Stüker D, Braun A, Schurr MO, Königsrainer A (2007) A new endoscopic over-the-scope clip system for treatment of lesions and bleeding in the GI tract: first clinical experiences. Gastrointest Endosc 66:162-167

7. Schurr MO, Hartmann C, Kirschniak A, Ho CN, Fleisch C, Buess G (2008) Experimental study on a new method for colonoscopic closure of large-bowel perforations with OTSC clip [in German]. Biomed Tech (Berl) 53:45-51

8. Schurr MO, Hartmann C, Ho CN, Kirschniak A (2008) An overthe-scope clip (OTSC) system for closure of iatrogenic colon perforations: results of an experimental survival study in pigs. Endoscopy 40:584-588

9. Matthes K, Jung Y, Kato M, Gromski MA, Chuttani R (2011) Efficacy of full-thickness GI perforation closure with a novel over-the-scope clip application device: an animal study. Gastrointest Endosc 74:1369-1375

10. Naegel A, Bolz J, Zopf Y, Matthes K, Mueller B, Kraus F, Neurath MF, Maiss J (2012) Hemodynamic efficacy of the overthe-scope clip in an established porcine cadaveric model for spurting bleeding. Gastrointest Endosc 75:152-159

11. Chung IK, Lee JH, Lee SH, Kim SJ, Cho JY, Cho WY, Hwangbo Y, Keum BR, Park JJ, Chun HJ, Kim HJ, Kim JJ, Ji SR, Seol SY (2009) Therapeutic outcomes in 1,000 cases of endoscopic submucosal dissection for early gastric neoplasms: Korean ESD Study Group multicenter study. Gastrointest Endosc 69: $1228-1235$

12. Goto O, Fujishiro M, Kodashima S, Ono S, Niimi K, Hirano K, Yamamichi N, Koike K (2010) A second-look endoscopy after endoscopic submucosal dissection for gastric epithelial neoplasm may be unnecessary: a retrospective analysis of postendoscopic submucosal dissection bleedings. Gastrointest Endosc 71: 241-248

13. Oka S, Tanaka S, Kaneko I, Mouri R, Hirata M, Kawamura T, Yoshihara M, Chayama K (2006) Advantage of endoscopic submucosal dissection compared with EMR for early gastric cancer. Gastrointest Endosc 64:877-883

14. Lee BI, Kim BW, Kim HK, Choi H, Ji JS, Hwang SM, Cho YS, Chae HS, Choi KY (2011) Routine mucosal closure with a detachable snare and clips after endoscopic submucosal dissection for gastric epithelial neoplasm: a randomized controlled trial. Gut Liver 5:454-459

15. Kantsevoy SV, Bitner M, Mitrakov AA, Thuluvath PJ (2013) Endoscopic suturing closure of large mucosal defects after endoscopic submucosal dissection is technically feasible, fast, and eliminates the need for hospitalization (with videos). Gastrointest Endosc 79(3):503-507. doi:10.1016/j.gie.2013.10.051 